\title{
Development and evaluation of the retail cuts, yields and sensory properties of smoked grasscutter (Tryonomys swinderianus)
}

\section{Peter Akhere Ebabhamiegbebho, John Oamen Igene and Smith Etareri Evivie*}

Food Science and Technology Unit, Department of Animal Science, Faculty of Agriculture, University of Benin, Benin city, NIGERIA

*Corresponding author. E-mail: besta_intercom@yahoo.com

Received: April 20, 2014; Revised received: May 2, 2014; Accepted: May 25, 2014

Abstract: The study was carried out to develop retail cuts, evaluate the effect of the method of pelage (removal/ scalding) on the yield and organoleptic quality of smoked grasscutter (Tryonomys swinderianus). Sixteen grass cutters were purchased from Abico bush meat market in Benin City, Nigeria. The pelages were removed by water and fire scalding. Some were brined in $15 \%$ salt solution for $3 \mathrm{hrs}$ while others were not. The carcasses were cut into seven retail cuts. All samples were smoke-dried for $6 \mathrm{hrs}$. Sensory evaluation was done by a 12-man panel using a 5 -point hedonic scale. The results showed that there were significant differences $(P<0.05)$ in the yield of fresh salted and non-salted grass cutter samples. There was also significant difference $(P<0.05)$ in the smoked yield of salted smoked grasscutter with WSS giving the highest yield of $1.03 \mathrm{~kg}$. The method of pelage removal did not have any significant effect $(P>0.05)$ but there was significant effects in the smoked yields. Sensory evaluation showed significant differences $(P<0.05)$ in the colour, tenderness, juiciness, flavor and overall acceptability. Salted samples had the highest scores all organoleptic properties. It was recommended that further studies be carried out to evaluate the effects of salting and smoking on economic and sensory parameters of other sources of bush meat in Nigeria.

Keywords: Development, Grasscutter, Retail cuts, Salting

\section{INTRODUCTION}

The processing and smoking of game meat in Nigeria has been a long time practice. In the southern parts of Nigeria, the hunting and processing of game animals as sources of animal protein is well known (Abioye et al., 2008; Ebabhamiegbebho and Ohanaka, 2012). Amongst these animals are the bush pigs, antelope, grassccutters (Tryonomys swinderianus), also called cane rats, deer, porcupine and the giant rats, etc. The consumption of game meat is increasing and breakthroughs have been made in the domestication of some of these game; such as grass cutter (T. swinderianus), (Addo, 2002; Adjanahoun, 2002; Olomu et al., 2003). The grasscutters also called cane rats are widely distributed and valuable game meat animals in West Africa. The value of the grasscutter as meat lies in its contribution to the nutrition of an individual in terms of animal protein supply. It is the bush meat of the consumer's first choice, as it has been reported to have higher nutritional value and meat yield than other traditional livestock species (Jori and Chardonnet, 2001; Ebabhamiegbebho and Ohanaka, 2012). The meat is the most cherished and sought after of all the game meat and has contributed in no small measure to the animal protein supply in the forest zones of Nigerian and other African countries. Grasscutter meat has a very high nutritive value; the crude protein content is about $22.7 \%$ as compared to $20.7 \%$ for rabbit, $19.2 \%$ for chicken meat, $18.2 \%$ for beef and $22.2 \%$ for turkey meat (Olomu et al., 2003). It has $16.8 \%$ crude fat; $2.9 \%$ ash; $320 \mathrm{mg} / 100 \mathrm{gm}$ (raw muscle) calcium; 380 mg of phosphorus; $20 \mathrm{mg}$ iron (Olomu et al., 2003; Okpara et al., 2006; Okpara and Fagbemi, 2008a and 2008b). The acceptance and consumption of this meat goes beyond the shores of Nigeria. In Ghana for instance, grassccutter meat out of all the bush meat exported, still dominates the bush meat trade. It is presently exported to United States of America and Europe (Ntiamo-Baidu, 1998; Kamwi, 2002). International trade as well as regional and continental interest in the grass cutter meat provides economic basis for the development of the grass cutter processing industry in Nigeria.

The grasscutter is widely accepted and processed throughout the South, South of Nigeria. It is a common site to see them processed, pierced through with sticks and hung along major highways. In Edo State, for instance, there are major bush meat markets, the grasscutter being the most common among them followed by the antelope and others. The processors only sell the whole intact processed grasscutter (Elumelu, 2010). This is very expensive, as the prices range between $\mathrm{N} 4,000$ to $\mathrm{N} 12,000$ naira each. The 
meat is usually sold whole after smoke-drying; without cutting into retail parts (cuts). This makes it unaffordable to low and medium income earners, who would have liked to consume the meat. The other larger bush meats such as the antelope, deer and bush pigs are however usually cut into retail parts, before they are smoked and sold. Preliminary findings showed that consumers preferred it sold in retail cuts; but that the grasscutter processors are skeptical about breaking "even", if they sell in retail cuts (Elumelu, 2010; Enuenweuche, 2010; Nwanade et al., 2011). The result is a product that would be on display for many days and as such deterioration and subsequently spoilage usually set in. Therefore the need to proposed workable retail cuts of grasscutter, which would result in larger consumers, more frequent sales and higher returns.

Some works have been done on its availability and domestication (Bifarin et al., 2008; Olomu et al., 2003). However, little or no work has been done in terms of its processing technology, product improvement, determination of retail cuts and their yields with respect to the whole carcass. The capturing, processing and marketing of this highly priced animal protein source remain in the hands of the peasant producers and marketers (Nwanade et al., 2011). Thus, the processing and quality control of its products are being compromised; but which remain a major challenge in the supply of quality game meats (Bifarin et al., 2008). The processing, distribution and marketing of grassccutter meat is at present a challenge for national food security regarding the poor expectations in terms of product quality, handling, organoleptic properties and packaging (Opara and Fagbemi, 2008a and 2008b). The need therefore for scientific transformation of the whole process becomes imperative. The objective of this study was to attempt to develop retail cuts value of smoked grasscutters. It was also, to determine the effect of the method of pelage removal (scalding) and addition of sodium chloride (salt) on the yields of the various retail cuts (parts), as related to whole, as well as the organoleptic qualities of smoked grasscutter.

\section{MATERIALS AND METHODS}

Procurement of raw materials (Grasscutters): Sixteen freshly gunshot grasscutters were purchased from Abico bush meat market in Benin City, Edo State. They were transported in picnic boxes to the laboratory for removal of the pelage/bristles (scalding) and the Entrails. Three commercially smoke-dried grasscutters on retail (GOR) which was the control were also purchased and transported in picnic box.

Processing of the grasscutters: The pelage (bristles) were removed using two methods: (i) The grasscutters were immersed in hot water $\left(80^{\circ} \mathrm{C}\right)$ for 60 secs and the pelage scrapped off using a blunt knife (Water scalding, WS); (ii) The others were placed on wire mesh over a glowing fire to burn off the bristles (Fire scalding; FS). The grasscutters were neatly eviscerated and the entrails removed (Aduku and Olukosi, 2000). The carcasses were then weighed and the yield recorded. Four each of the WS and FS of the dressed carcasses were separately immersed in $15 \%$ salt solution for $3 \mathrm{hs}$ (WSS and FSS) at room temperature $\left(25-28^{\circ} \mathrm{C}\right)$. The changes in weights were recorded (Ebabhamiegbebho et al., 2011). The FS salted (FSS) and the WS salted (WSS) were cut into proposed retail cuts of seven portions. The FS not salted (FSNS) and the WS not salted (WSNS) were also cut into seven (7) retail cuts. All the parts were weighed using a laboratory scale. The percentage proportions of each part with regard to the whole carcass were also determined and recorded. The smoked samples were designated as WSS, WSNS, FSS, and FSNS for the water scalded salted smoked, water scalded not salted smoked, fire scalded salted smoked and fire scalded not salted smoked respectively. The parts were right hind limb (RHL), left hind limb (LHL), right forelimb (RFL), left forelimb (LFL), right abdomen (RA), left abdomen (LA) and head (H) (Paulsen, 2009).

Smoke drying of the samples: The grasscutter samples were smoked-dried for six hours at a temperature of $60-65^{\circ} \mathrm{C}$ in a Model atona smoking kiln using Rubber (Hevea brasillensis) wood (Abolagba et al., 2002; Abolagba and Odiko, 2005). The rate of moisture loss was determined by taking the weights of the samples every 1 hour for 6hours. The drying rate graphs were plotted to determine the drying behavior of the treatment samples.

Sensory evaluation: A 12-man member panel was used for the organoleptic evaluation of colour, flavor, texture, tenderness and overall acceptability based on a 5-point Hedonic scale. The scoring of the samples ranged from 1(dislike extremely) to 3(neither like nor dislike) to 5 (like extremely) (Kilcast, 2003; Okaka, 2010).

Non-standard abbreviations: FSS: Fire scalded salted, FSNS: Fire scalded not salted, WSS: Water scalded salted, WSNS: Water scalded not salted.

\section{RESULTS AND DISCUSSION}

The results of the effect of addition of $15 \%$ salt solution by immersing freshly dressed retail cuts of grasscutter in the solution is presented in table 1 . The results are presented as absolute weight of each cut and their percentage contribution to the whole carcass. The right hind limb of the FSS and FSNS showed that each of them weighed $0.98 \mathrm{~kg}$ representing $20.21 \%$ and 0.94 $\mathrm{kg}$ representing $23.15 \%$ respectively. There was no significant difference $(P>0.05)$ in their yields. The WSS and theWSNS had weights of $1.03 \mathrm{~kg}$ representing $22.10 \%$ and $0.99 \mathrm{~kg}$ representing $22.65 \%$. There was no significant difference $(\mathrm{P}>0.05)$ in their yields. There was also no significant difference $(P>0.05)$ in the right and left abdominal parts and the head. 
Table 1. Effect of salting on the yields of fresh retail cuts of grasscutter.

\begin{tabular}{|c|c|c|c|c|c|c|c|c|c|c|}
\hline \multirow{2}{*}{ Retail cuts } & \multicolumn{2}{|c|}{ FSS } & \multicolumn{2}{|c|}{ FSNS } & \multirow{2}{*}{ SEM } & \multicolumn{2}{|c|}{ WSS } & \multicolumn{2}{|c|}{ WSNS } & \multirow{2}{*}{ SEM } \\
\hline & Kg & $\%$ & Kg & $\%$ & & $\mathbf{K g}$ & $\%$ & Kg & $\%$ & \\
\hline Right hind limb(RHL) & $0.98 \mathrm{a}$ & 20.21 & $0.94 a$ & 23.15 & \pm 0.01 & $1.03 \mathrm{a}$ & 22.10 & $0.99 a$ & 22.56 & \pm 0.02 \\
\hline Left hind limb (LHL) & $0.90 \mathrm{a}$ & 18.56 & $0.61 b$ & 15.05 & \pm 0.01 & $0.90 \mathrm{a}$ & 19.31 & $0.73 a$ & 16.71 & \pm 0.01 \\
\hline Right forelimb(RFL) & $0.91 \mathrm{a}$ & 18.76 & $0.67 b$ & 16.50 & \pm 0.03 & $0.93 a$ & 19.96 & $0.65 a$ & 14.87 & \pm 0.01 \\
\hline Left forelimb(LFL) & $0.73 \mathrm{a}$ & 15.05 & $0.49 b$ & 12.07 & \pm 0.02 & $0.54 \mathrm{a}$ & 11.59 & $0.50 \mathrm{a}$ & 11.44 & \pm 0.03 \\
\hline Right abdomen(RA) & $0.48 \mathrm{a}$ & 9.90 & $0.44 \mathrm{a}$ & 10.84 & \pm 0.04 & $0.40 \mathrm{a}$ & 8.85 & $0.48 \mathrm{a}$ & 10.98 & \pm 0.01 \\
\hline Left abdomen(LA) & $0.39 a$ & 8.04 & $0.43 \mathrm{a}$ & 10.59 & \pm 0.02 & $0.38 \mathrm{a}$ & 8.15 & $0.42 \mathrm{a}$ & 9.61 & \pm 0.02 \\
\hline $\operatorname{Head}(\mathrm{H})$ & $0.46 \mathrm{a}$ & 9.48 & $0.43 \mathrm{a}$ & 10.59 & \pm 0.03 & $0.48 \mathrm{a}$ & 10.30 & $0.60 \mathrm{~b}$ & 13.73 & \pm 0.02 \\
\hline Total & $4.85 \mathrm{a}$ & 100.00 & $4.06 \mathrm{~b}$ & 100.00 & \pm 0.02 & $4.66 \mathrm{a}$ & 100.00 & $4.37 \mathrm{~b}$ & 100.00 & \pm 0.01 \\
\hline
\end{tabular}

Means with same letter within same rows are not significantly different $(\mathrm{P}>0.05)$; FSS = Fire scalded salted; FSNS = Fire scalded not salted; WSS $=$ Water scalded salted and WSNS $=$ Water scalded not salted.

Table 2. Effect of method of scalding (pelage removal) on the yields of smoke-dried retail cuts of grasscutter.

\begin{tabular}{|c|c|c|c|c|c|c|c|c|c|c|}
\hline \multirow[t]{2}{*}{ Retail cuts } & \multicolumn{2}{|c|}{ FSSS } & \multicolumn{2}{|c|}{ WSSS } & \multirow[t]{2}{*}{ SEM } & \multicolumn{2}{|c|}{ FSNS } & \multicolumn{2}{|c|}{ WSNS } & \multirow[t]{2}{*}{ SEM } \\
\hline & $\overline{\mathrm{Kg}}$ & $\%$ & Kg & $\%$ & & Kg & $\%$ & Kg & $\%$ & \\
\hline Right hind limb & $0.40 \mathrm{a}$ & 22.47 & $0.44 a$ & 20.46 & \pm 0.02 & $0.43 a$ & 22.87 & $0.49 b$ & 21.59 & \pm 0.01 \\
\hline Left hind limb & 0.33 & 18.54 & $0.41 b$ & 19.07 & \pm 0.02 & $0.35 \mathrm{a}$ & 18.62 & $0.41 b$ & 18.06 & \pm 0.01 \\
\hline Right fore hind & $0.03 \mathrm{a}$ & 16.85 & $0.37 b$ & 17.21 & \pm 0.05 & $0.31 \mathrm{a}$ & 16.49 & $0.39 b$ & 17.18 & \pm 0.02 \\
\hline Left fore hind & $0.21 \mathrm{a}$ & 11.80 & $0.33 b$ & 15.35 & \pm 0.03 & $0.23 \mathrm{a}$ & 12.23 & $0.35 b$ & 15.42 & \pm 0.03 \\
\hline Right abdomen & $0.19 \mathrm{a}$ & 10.67 & $0.19 a$ & 8.84 & \pm 0.04 & $0.18 \mathrm{a}$ & 9.59 & $0.20 \mathrm{a}$ & 8.81 & \pm 0.02 \\
\hline Left abdomen & $0.12 \mathrm{a}$ & 6.74 & $0.14 \mathrm{a}$ & 6.51 & \pm 0.01 & $0.13 \mathrm{a}$ & 6.92 & $0.15 \mathrm{a}$ & 6.61 & \pm 0.02 \\
\hline Head & $0.23 \mathrm{a}$ & 12.92 & $0.27 \mathrm{a}$ & 12.56 & \pm 0.02 & $0.25 \mathrm{a}$ & 13.30 & $0.28 \mathrm{a}$ & 12.33 & \pm 0.01 \\
\hline Total & $1.78 \mathrm{a}$ & 100.00 & $2.15 b$ & 100.00 & \pm 0.02 & $1.88 \mathrm{a}$ & 100.00 & $2.27 \mathrm{~b}$ & 100.00 & \pm 0.01 \\
\hline
\end{tabular}

Means with same letter within same rows are not significantly different $(\mathrm{P}>0.05)$; FSS $=$ Fire scalded salted; FSNS $=$ Fire scalded not salted; WSS $=$ Water scalded salted and WSNS $=$ Water scalded not salted.

However significant differences $(P<0.05)$ were observed in the yields of the left hind limb, right and left forelimbs as well as the total yields of the FSS and FSNS grasscutter. These differences may be due to the addition of salt. It was reported in an earlier study that the addition of salt resulted in the yield of smoked beef and that there was significant difference $(\mathrm{P}<0.05)$ in the salted and the not salted smoked beef (Ebabhamiegbebho et al., 2011). There was also no significant difference $(\mathrm{P}>0.05)$ observed in the right and left abdominal portions of the FSS and FSNS. The result also showed no significant difference $(P>0.05)$ in the fresh yield of the right hind limb, left forelimbs and right and abdominal parts of the WSSS) and WSNS. There was however significant difference $(\mathrm{P}<0.05)$ in the yields of the left hind limb right forelimb, the head and the total yield. These differences maybe attributable to the addition of sodium chloride (salt) to the fresh meat for $3 \mathrm{hrs}$. This is achieved by the salt chemically binding to the water molecules, thereby preventing the molecules from being released from the meat. This results in the yield, tenderness and extended shelf life of the meat. The salt also prevents microbial invasion by making the water molecules unavailable for activities of pathogenic microorganisms and subsequent spoilage of meat.

The results of the yields of the smoked-dried samples (FSS, FSNS, WSS and WSNS) are presented in table 2. The result revealed that there were significant differences $(\mathrm{P}<0.05)$ in the right hind limb, right and left abdominal portions as well as the head. There was however, no significant difference in the left hind limb, right and left forelimbs and the total yields of the products of the FSS and FSNS of smoked grasscutter. Again these differences observed may be due to the effective and uniform method of addition of salt to these samples prior to smoke- drying (Paulsen, 2009; Ebabhamiegbebho et al., 2011). There were significant differences $(\mathrm{P}<0.05)$ in the right and left hind limb, right and left forelimbs and the total yields of the smoke-dried WSS and WSNS grasscutter; whereas,

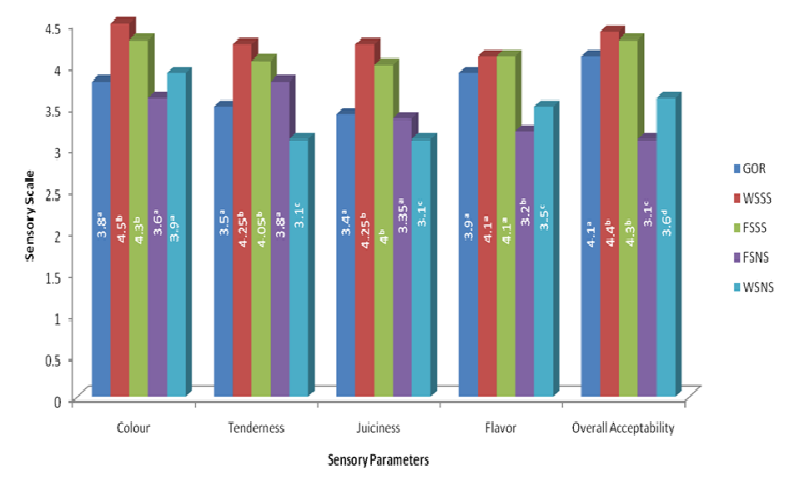

Fig. 1. Sensory quality scores for the salted grasscutter. Means across bars with same superscripts are not significantly different $(P>0.05) ; G O R=$ Grasscutter on retail, WSSS $=$ Water scalded Salted Smoked, WSNS = Water Scalded not salted smoked dried grasscutter, FSNS = Fire Scalded not salted smoked dried grasscutter, FSSS $=$ Fire Scalded salted smoked grasscutter. 
Table 3. Effect of the method of scalding (pelage removal) on the yield of fresh retail cuts of grasscutter.

\begin{tabular}{|c|c|c|c|c|c|c|c|c|c|c|}
\hline \multirow[t]{2}{*}{ Retail cuts } & \multicolumn{2}{|c|}{ FSS } & \multicolumn{2}{|c|}{ WSS } & \multirow[t]{2}{*}{ SEM } & \multicolumn{2}{|c|}{ FSNS } & \multicolumn{2}{|c|}{ WSNS } & \multirow[t]{2}{*}{ SEM } \\
\hline & Kg & $\%$ & Kg & $\%$ & & $\mathbf{K g}$ & $\%$ & Kg & $\%$ & \\
\hline Right hind limb & $0.84 a$ & 20.24 & $1.10 \mathrm{~b}$ & 25.35 & \pm 0.03 & $0.94 \mathrm{a}$ & 20.44 & $0.98 \mathrm{a}$ & 20.42 & \pm 0.02 \\
\hline Left hind limb & $0.63 a$ & 15.58 & $0.75 a$ & 17.28 & \pm 0.02 & $0.88 \mathrm{a}$ & 19.13 & $0.90 \mathrm{a}$ & 18.75 & \pm 0.02 \\
\hline Right forelimb & $0.86 \mathrm{a}$ & 20.72 & $0.98 b$ & 22.58 & \pm 0.01 & $0.85 a$ & 18.48 & $0.90 \mathrm{a}$ & 18.75 & \pm 0.02 \\
\hline Left forelimb & $0.65 a$ & 15.66 & $0.53 b$ & 12.21 & \pm 0.02 & $0.81 \mathrm{a}$ & 17.38 & $0.83 a$ & 17.29 & \pm 0.04 \\
\hline Right abdomen & $0.43 a$ & 10.36 & $0.25 b$ & 5.76 & \pm 0.02 & $0.36 \mathrm{a}$ & 7.83 & $0.40 \mathrm{a}$ & 8.33 & \pm 0.04 \\
\hline Left abdomen & $0.28 \mathrm{a}$ & 6.75 & $0.25 \mathrm{a}$ & 5.76 & \pm 0.01 & $0.28 \mathrm{a}$ & 6.09 & $0.31 \mathrm{a}$ & 6.46 & \pm 0.02 \\
\hline Head & $0.46 a$ & 11.08 & $0.48 \mathrm{a}$ & 11.06 & \pm 0.01 & $0.49 a$ & 10.65 & $0.48 \mathrm{a}$ & 10.00 & \pm 0.01 \\
\hline Total & $4.15 \mathrm{a}$ & 100.00 & $4.34 \mathrm{a}$ & 100.00 & \pm 0.02 & $4.60 \mathrm{a}$ & 100.00 & $4.80 \mathrm{a}$ & 100.00 & \pm 0.02 \\
\hline
\end{tabular}

Means with same letter within same rows are not significantly different $(\mathrm{P}>0.05)$; FSS $=$ Fire scalded salted, FSNS $=$ Fire scalded not salted, WSS $=$ Water scalded salted and WSNS $=$ Water scalded not salted.

Table 4. Effects of method of scalding (pelage removal) on the yields of smoke-dried retail cuts of grasscutter.

\begin{tabular}{|c|c|c|c|c|c|c|c|c|c|c|}
\hline \multirow[t]{2}{*}{ Retail cuts } & \multicolumn{2}{|c|}{ FSS } & \multicolumn{2}{|c|}{ WSS } & \multirow[t]{2}{*}{ SEM } & \multicolumn{2}{|c|}{ FSNS } & \multicolumn{2}{|c|}{ WSNS } & \multirow[t]{2}{*}{ SEM } \\
\hline & Kg & $\%$ & Kg & $\%$ & & $\mathbf{K g}$ & $\%$ & Kg & $\%$ & \\
\hline Right hind limb & $0.44 a$ & 19.73 & $0.48 \mathrm{a}$ & 21.53 & \pm 0.03 & $0.42 \mathrm{a}$ & 23.33 & $0.45 \mathrm{a}$ & 22.84 & \pm 0.03 \\
\hline Left hind limb & $0.42 \mathrm{a}$ & 18.83 & $0.42 \mathrm{a}$ & 18.83 & \pm 0.01 & $0.27 \mathrm{a}$ & 15.00 & $0.33 b$ & 16.75 & \pm 0.02 \\
\hline Right forelimb & $0.42 \mathrm{a}$ & 18.83 & $0.44 \mathrm{a}$ & 19.73 & \pm 0.04 & $0.30 \mathrm{a}$ & 16.67 & $0.31 \mathrm{a}$ & 15.74 & \pm 0.02 \\
\hline Left forelimb & $0.34 \mathrm{a}$ & 15.25 & $0.26 \mathrm{~b}$ & 11.66 & \pm 0.02 & $0.22 \mathrm{a}$ & 12.22 & $0.23 \mathrm{a}$ & 11.68 & \pm 0.01 \\
\hline Right abdomen & $0.22 \mathrm{a}$ & 9.87 & $0.19 \mathrm{a}$ & 8.52 & \pm 0.02 & $0.20 \mathrm{a}$ & 11.11 & $0.19 \mathrm{a}$ & 9.65 & \pm 0.02 \\
\hline Left abdomen & $0.18 \mathrm{a}$ & 8.07 & $0.18 \mathrm{a}$ & 8.07 & \pm 0.03 & $0.19 \mathrm{a}$ & 10.06 & $0.19 \mathrm{a}$ & 9.65 & \pm 0.03 \\
\hline Head & $0.21 \mathrm{a}$ & 9.42 & $0.26 \mathrm{~b}$ & 11.66 & \pm 0.02 & $0.21 \mathrm{a}$ & 11.67 & $0.27 \mathrm{~b}$ & 13.71 & \pm 0.01 \\
\hline Total & $2.23 \mathrm{a}$ & 100.00 & $2.23 \mathrm{a}$ & 100.00 & \pm 0.01 & $1.80 \mathrm{a}$ & 100.00 & $1.97 \mathrm{~b}$ & 100.00 & \pm 0.02 \\
\hline
\end{tabular}

Means with same letter within same rows are not significantly different $(\mathrm{P}>0.05)$; FSS = Fire scalded salted, FSNS = Fire scalded not salted, WSS $=$ Water scalded salted and WSNS $=$ Water scalded not salted.

there were no significant differences $(\mathrm{P}<0.05)$ in the right and left abdomen as well as the head portions of the WSS and WSNS smoke-dried grasscutter. These differences are attributable to the brining of samples in sodium chloride solution. The significant differences observed in the salted and not salted smoke-dried grasscutter confirmed the results obtained from the field (in previous studies) from commercial grasscutter processors. There were no significant differences in the yields of their products. This was due to the fact that, the grasscutter processors in Edo State Nigeria, do not add sodium chloride (salt) to their carcasses prior to smoke drying. The average yields recorded from the field range from $44 \%$ to $50 \%$. This agrees with the findings of this study that the average yields are between 45 to $50 \%$. This study further agrees with the findings of Hayta et al. (2002) which reported that processing methods amongst other factors affect the functional properties and yields of food.

The result on the effect of the method of pelage removal (scalding) on the yield of fresh retail cuts of grasscutter is shown in table 3 . The result showed significant differences $(P<0.05)$ in the right hind limb, right and left forelimbs as well as the right abdominal portions. There were no significant differences $(\mathrm{P}>$ 0.05 ) in the left hind limb, left abdominal portions, the head and the total yields of fresh retail cuts of FSS and WSS grasscutter. These differences may be due to the method of pelage removal. On the average, the water scalded and salted (WSS) yielded more $(4.34 \mathrm{~kg}$ ) than the fire scalded and salt $(4.15 \mathrm{~kg})$. This result again agrees with the preliminary field survey that showed that on the average, WS grasscutter samples yielded more than the FS; the reason why most $(90 \%)$ of grasscutter processors in Edo State practice water scalding. There was also no significant difference $(P>0.05)$ in all the retail cuts of fresh grasscutter of the FSNS and WSNS samples (Table 3). There was also no significant difference $(\mathrm{P}>0.05)$ in the total yields. This result is however in contrast to the field report which observed significant difference $(P<0.05)$ between the WSNS and FSNS samples. Therefore, it can be inferred that the significant differences observed in the FSS and WSS based on the method of pelage removal/ scalding may be due to the combined effect of the method of pelage removal and salting.

The result on the effect of method of scalding on the smoke-dried yield of grasscutter is presented in table 4 . There were significant differences $(\mathrm{P}<0.05)$ in the left forelimb and the head portions of the products of the FSS and WSS samples. There were however, no significant differences observed in other retail parts and the total yields of the smoked product. This may be due to the effective method of smoke drying the final product. Abolagba and Odiko (2005) had reported that effective smoke-drying of fish using specific hard wood resulted in higher yield and better quality of smoked fish. The result of the smoked FSNS and WSNS samples showed significant differences $(P<0.05)$ in the yields of the left hind limb and the 
total; no significant difference $(P<0.05)$ was observed in the other retail cuts of the carcass including the total of the smoke dried FSS and WSSS grasscutter samples. The total yields for the smoked FSNS and WSNS samples were $1.80 \mathrm{~kg}$ and $1.90 \mathrm{~kg}$ respectively. The result of the sensory evaluation of smoked grasscutter on different treatments and a control- the commercially processed grasscutter on retail (GOR) is shown in fig. 1. There was a significant difference $(P<0.05)$ in the colour score with the water scalded salted (WSS) having the highest score of 4.5 in a scale of 5. It was not significantly different $(P>0.05)$ from the fire scalded salted smoked (FSS) sample. These were significantly different $(P<0.05)$ from the other treatment samples, including the control (GOR). The control had the least score of 3.8 , but was not significantly different $(P>0.05)$ from the FSNS and WSNS in the colour score. The WSS and FSS samples were scored highest in tenderness, juiciness, flavor and overall acceptability. There was no significant difference $(P>0.05)$ between these, though the WSS was scored higher than the FSS in all parameters, except in flavor where both were scored 4.1 each. The WSS and FSS were significantly different $(P<0.05)$ from the FSNS, WSNS and GOR in these parameters. The WSS was the most acceptable of all the treatments with a score of 4.4. The score was not significantly different $(P>0.05)$ from the FSS; although, both were significantly different from the FSNS, WSNS and GOR. The general acceptance by consumers of the WSS and FSS grasscutter samples may be due to the addition of salt. The use of salt in enhancing the taste of food has been reported earlier (Ikene, 1990; Ebabhamiegbebho et al., 2011).

\section{Conclusion}

The study has shown that treating of samples with salt prior to smoking has the propensity to increase yield which is an important parameter in profit making. Salting also caused significant difference between WSNS and FSNS grasscutter samples. The method of pelaging used gave higher yields in WSS than FSS which agrees with field survey results in Edo State, Nigeria. WSS had the highest colour score and was the most acceptable of all treatments. WSS and FSS were scored highest in tenderness, juiciness, flavor and overall acceptability. It is recommended that further studies be carried out to evaluate the effects of salt and smoking on other wild animal species from which bush meat is obtained either for commercial or subsistence use.

\section{REFERENCES}

Abioye, F.O., Uda, A.C., Opara, M.N., Aju, P.C. and Onyema, M.C. (2008). Adaptability of grasscutter (Thryonomys swinderianus) in natural and domestic environment. Proceedings of the Conference of Forestry Association of Nig. Aug. 15-20 Uyo Akwa Ibom State pp. 537-55.
Abolagba, O.J. and Odiko, A.E. (2005). Effect of charcoal from Pentaclethra Macrophylla snd Rubber (Hevea brasillevsis) wood as Energy Sources on Quality of smoked fish. Nig. J. Appl. Sci., 23:45-49.

Abolagba, O.J., Uwakina, S. and Odiko, A.E. (2002). Utilization of Rubber Wood (Hevea brasillevsis) and saw dust as Energy sources on the characteristics of Smoked Fatty Fish. Appl. Fish. \& Aqua., 11(1):17-20.

Addo, P.G. (2002). Detection of mating, pregnancy and imminent Parturition in the grasscutter (Thryonomys swinderianus). Livestock Research for Rural Development, 14 (4) 8-13.

Aduku, A.O. and Olukosi, J.O. (2000). Animal products processing and handling in the tropics. Living books series. G. U. publications, P.O. Box 2280, Abuja, Nigeria.

Adjanahoun, E. (2002). Gestation dianosis of the grasscutter (Thryonomys swinderianus): Field and Laboratory methods. Proceedings of conference on grasscutter ptoduction. Cotonou, Benin, pp. 123-131.

Bifarin, J.O., Ajibola, M.E. and Fadiyimu, A.A. (2008). Analysis of marketing bush meat in Idanre Local Govt. Area of Ondo State, Nigeria. Afri. J. Agric. Res., 13 (10):667-671.

Ebabhamiegbebho, P.A., Igene, J.O. and Evivie, S.E. (2011). The effect of preservative methods on the yield water content and microbial stability of Dairy products. $J$. Appl. Sci. \& Environ. Manage., 15(2) 265-271.

Ebabhamiegbebho, P.A. and Ohanaka, M.C. (2012). Consumer preferences for different types of Bush meat sold in Benin City, Nigeria. J. Appl. Sci., 30:105-110.

Elumelu, B.I. (2010). Assessment of the Sources of Bushmeat supplies in Benin City. Final year project, Department of Animal Science, University of Benin, Nigeria

Enuenweuche, U.I., (2010). Evaluation of the different processing methods of grasscutters meat in Ovia North East and Egor LGA of Edo State Final Year project, Department of Animal Science, University of Benin, Nigeria.

Hayta, M., Alpalsan, M. and Bayasar, A. (2002). Effect of drying methods on functional properties of tarhana: A wheat flour-yoghurt mixture. J. Food Sci., 67(2):740744.

Ikeme, A.I. (1990). Meat science and technology: A comprehensive approach. African FEP Publishers Limited, Onitsha, Nigeria.

Jori, F. and Chardonnet, P. (2001). Grass cutter farmig in Gabon. Status and Perspective. Paper presented at the $5^{\text {th }}$ International Wildlife Ranching Symposium, Pretoria, South Africa. March, pp 33-51.

Kamwi, J.A. (2002). Export of namibian game meat /carcass for commercial purposes. Letter addressed to Game Meat products tasks team. Ministry of Agric. Water and forestry Windhoek. Namibia.

Kilcast, D. (2003). Sensory evaluation methods for shelf life assessment: In the stability and shelf life of food. $C R C$ press Woodhead pub. Com. Cambridge.

Nwanade, C.F., Ebabhamiegbebho, P.A. and Igene, J.O. (2011). Lipid and Microbial Evaluation of grasscutter on retail. Proceedings of the $35^{\text {th }}$ NIFST Conference in Makurdi, Benue State 10-14 ${ }^{\text {th }}$ October 2011. pp. 10 and 11.

Ntiamo-Baiu, Y. (1998). Sustainable use of bushmeat VI, 78pp. Vol. 6. Wildlife development plan1998-2003. 
Wildlife department Accra.Biological Conservation, 6:32-39.

Okaka, J.C. (2010). Teach yourself sensory evaluation and experimentation. OJC Food Consultants. Academic Publishers, Enugun. pp.1-82.

Olomu, J.M., Ezieshi, V.E. and Orheruata, A.M. (2003). Grasscutter production in Nigeria: Principles and Practice. Jachem publ. Benin City.

Opara, M.N., Ike, K.A. and Okoli, I.C. (2006). Heamatology and Plasma biochemistry of the wild adult African grasscutter (Thryonomys swinderianus. Temmink). J. Anim. Sci., 2(2): 17-22.

Opara, M.N. and Fagbemi, B.O. (2008a). Observations on the Gastrointestinal Helminth parasites of the wild Grasscutter (Thryonomys swinderianus, Temminck) in Imo State, Nigeria. Int. J. Trop. Agric. \& Food Sys., 2 (1):105-110.

Opara, M.N. and Fagbemi, B.O. (2008b). Haematological and plasma biochemistry of Adult Wild African
Grasscutter (Thryonomys swinderianus): A Zoonosis Factor in the Tropical Humid Rainforest of Southeast Nigeria. Ann. New York Acad. Sci., 1149:394-397.

Paulson, P. (2009). Microbiological safety and quality of meat cuts and meat products from game. Proceedings of the International Conference organized by International Research Forum on Game Meat Hygiene (IRFGMH): Game Meat Hygiene in Focus at the University of Veterinary and Pharmaceutical Sciences Brno, Palackeho 1-3, Brno Czech Republic $18^{\text {th }}-19^{\text {th }}$ June 2009. pp. 4.

Wagner, K. (2012). A nutritionist's view on game meat. In: Proceedings of the International Research Forum for Game Meat Hygiene (IRFGMH): Game Meat Hygiene in Focus, held at the Institute of Meat Hygiene, Meat Technology and Food Science, University of Veterinary Medicine, Vienna, Austria. $11^{\text {th }}-12^{\text {th }}$ October 2012. Editors: Bauer A, Paulson.P. and Smulders, F.J.M. pp. 26. 